\title{
História natural da hepatite crônica B
}

\author{
Natural history of chronic hepatitis B
}

\author{
José Carlos Ferraz da Fonseca ${ }^{1}$
}

\begin{abstract}
RESUMO
Estima-se que existam 350 milhões de portadores crônicos do VHB distribuídos ao redor do mundo. Três fases de infecção crônica pelo VHB são reconhecidas: fase de imunotolerância (HBsAg e HBeAg positivos, altos títulos de HBV-DNA, ALT normal e não evidência de doença hepática ativa); fase imunoativa ou de hepatite crônica B (HBsAg e HBeAg positivos, altos títulos de HBV-DNA, ALT elevada e evidência de doença hepática ativa); fase de portador inativo do VHB ou assintomático (HBsAg no soro sem o HBeAg, títulos do HBV-DNA < 105 cópias p/ml, ALT normal). Hepatite crônica B é dividida em duas formas maiores: doença HBeAg positiva (VHB tipo selvagem); doença HBeAg negativa (pré-core, core promoter VHB variante). As duas formas podem evoluir para cirrose hepática, descompensação hepática e câncer hepático. A proposta deste artigo foi o de rever os principais aspectos da história natural da hepatite crônica $B$.
\end{abstract}

Palavras-chaves: Vírus da hepatite B. História natural. Hepatite crônica. Cirrose hepática

\section{ABSTRACT}

An estimated 350 million people worldwide are chronically infected with hepatitis B virus (HBV). Three phases of chronic hepatitis B virus infection is are recognized: the immune tolerant phase (HBeAg-positive, high levels of serum HBV-DNA, normal ALT, and no evidence of active liver diseases), the immune clearance phase or chronic hepatitis phase (HBeAg-positive, high levels of serum HBV-DNA, elevated ALT, and active liver disease), and the inactive carrier state or asymptomatic phase (HBsAg-positive in serum without HBeAg, HBV-DNA levels than < $10^{5}$ copies/mL, and normal ALT levels). Chronic hepatitis B is classified into 2 major forms: HBeAg-positive disease (wild-type HBV) and HBeAg negative disease (pre-core/core promoter HBV variant). Both forms can lead to liver cirrhosis, hepatic decompensation and liver cancer. The purpose of this article is to review the principal aspects of natural history of chronic hepatitis $B$.

Key-words: Hepatitis B virus. Natural history. Chronic hepatitis. Liver cirrhosis.

A infecção pelo vírus da hepatite B (VHB) é um dos mais sérios problemas de Saúde Pública no mundo. Estima-se que existam aproximadamente 350 milhões de portadores crônicos desse vírus distribuídos em várias regiões do mundo ${ }^{24}$. Um milhão de pessoas ao redor do mundo morrem anualmente em consequiência de doença hepática crônica $\mathrm{B}^{24}$. Ásia, Pacífico Sul e África têm a maior incidência e prevalência no mundo ${ }^{23} 32$, enquanto, no Brasil, o cerne do problema estaria localizado na região Amazônica brasileira, em especial na Amazônia Ocidental ${ }^{11}$. Em áreas sabidamente endêmicas de infecção pelo VHB, como na Ásia ${ }^{23}$, prevalece a transmissão vertical (mãefilho), exceto na Amazônia brasileira ${ }^{11}$. Em outras áreas, a transmissão do VHB é geralmente horizontal (per cutânea, sexual) ${ }^{2324}$.

\section{CARACTERÍSTICAS BIOLÓGICAS DO VÍRUS DA HEPATITE B}

Com tropismo pela célula hepática, classifica-se atualmente $o$ vírus da hepatite $B$ como protótipo de um vírus pertencente à família hepadnaviridae ${ }^{21}$. 0 natural hospedeiro do VHB é 0 ser humano, mas vírus similares constituídos de DNA foram isolados em animais, tais como: marmotas (woodchuck hepatitis virus- WHV), esquilos (ground squirrel heaptitis virus-GSHV), patos (duck hepatitis B virus), garças (heron hepatitis B virus), gansos (goose hepatitis B virus) e outros tipos de pássaros (crane hepatitis B $)^{21}$. Apesar dos hepadnavirus terem uma preferência pelas células hepáticas, partículas de DNA de hepadnavirus foram observadas nos rins, pâncreas e células mononucleares ${ }^{21}$. Seu pequeno genoma é constituído por ácido desoxirribonucléico (HBV-DNA), contendo 3.200 nucleotídeos e peso molecular de $3.2 \mathrm{~kb}^{16}$. 0 VHB replica-se por via transcriptase reversa e o gene do VHB tem ordem, número e sequiência genômica homólogos aos de certos retrovírus ${ }^{1621}$.

0 vírus B circula primariamente no sangue e replica-se nos hepatócitos em torno de $10^{11}(100.000 .000 .000$ cópias $\mathrm{m} / \mathrm{l}) \mathrm{x}$ por dia, enquanto os vírus da hepatite C (VHC) e da imunodeficiência (HIV) próximo de $10^{9}(1.000 .000 .000$ cópias $\mathrm{m} / \mathrm{l})$ por $\mathrm{dia}^{212930}$. 0 vírus B sobrevive até uma semana fora do corpo humano 2930 .

\footnotetext{
1. Faculdade de Ciências da Saúde, Universidade Federal do Amazonas, Manaus, AM

Endereço para correspondência: Prof. José Carlos Ferraz da Fonseca. Rua Soure, Quadra 9, Casa 1, Bairro Dom Pedro, 69040-570 Manaus, AM.

e-mail: jcfonseca@vivax.com.br, drjcfonseca@gmail.com

Recebido para publicação em: 26/09/2007

Aceito em: 03/12/2007
} 
No plasma, a vida média do VHB varia de um dia a três dias, enquanto nos hepatócitos a vida média varia de 10 dias100 dias $^{2930}$. A alta produção de virions influencia na produção do VHB mutante ${ }^{29} 30$. 0 vírus é altamente infectivo e sabe-se que uma só partícula viral é capaz de infectar o ser humano.

Quatro antígenos são produzidos pelo genoma do VHB: a) antígeno de superfície do VHB (HBsAg), b) antígeno $e$ do VHB (HBeAg), c) antígeno central (core) do VHB (HBcAg), d) antígeno $x$ do VHB (HBxAg). A exata função do HBxAg durante a replicação do VHB e sua influência associada a carcinogenese hepática, ainda não está bem definida ${ }^{2}$. Contudo, estudos experimentais sugerem que a expressão continua do HBxAg nos hepatócitos possa influenciar a transformação celular ${ }^{2}$.

Antes da introdução do teste HBV-DNA por PCR, o HBeAg foi utilizado como um marcador da replicação ativa e infectividade do VHB, como também usado como critério para o tratamento. A função biológica do HBeAg no ciclo da vida do VHB é controversa, todavia a simples presença sérica deste antígeno entre portadores do VHB $\left(\mathrm{HBsAg}^{+}\right)$, teria uma importância fundamental na história natural da hepatite crônica $\mathrm{B}^{2541}$.

0 HBeAg é derivado do produto da translação das regiões core e pré-core do $\mathrm{VHB}$, ou seja, produto secretório do $\mathrm{HBcAg}^{21}$. Indivíduos portadores do $\mathrm{HB} e \mathrm{Ag}$ apresentam altos títulos $\left(10^{8}-10^{11}\right)$ de partículas virais $\mathrm{p} / \mathrm{mL}$ (sangue), ao passo que o número de partículas virais é bem menor entre indivíduos $\mathrm{HB} e \mathrm{Ag}$ negativos (anti-HBe+), 105-107 cópias $^{16} 1821253033$. 0 uso de potentes drogas inibidoras contra o VHB geralmente resulta em decréscimo dos títulos do HBV-DNA, todavia uma significativa parte dos pacientes não consegue perder o $\mathrm{HB} e \mathrm{Ag}$. Estes achados reforçam a hipótese de que o $\mathrm{HB} e \mathrm{Ag}$ seja um marcador do número de células infectadas ${ }^{34}$. A persistência e a positividade do HBeAg está associada ao aumento de risco para carcinoma hepatocelular ${ }^{41}$. Estudos consistentes sugerem que a função do HBeAg seria a de induzir o estado de imunotolerância do VHB, o estabelecimento do estado de portador crônico e a repressão da replicação do HBV-DNA ${ }^{2134}$.

Apresentando uma diversidade viral complexa, o VHB apresenta diferentes subtipos e genótipos ${ }^{21}$. Diferenças antigênicas no antígeno de superfície do vírus B (HBsAg) estabelecem quatro subtipos: $a d w$, ayw $a d r$, e ayr. Correntemente o VHB é dividido em oito genótipos (A, B, C, D, E, F, G, H), que são associados com diferentes mutações nas regiões dos genes pré-core e promoter core basal durante a soroconversão do $\mathrm{HB} e \mathrm{Ag}$ para anti-HB $e^{21}$. Estudos recentes sugerem que os genótipos do VHB possam influir na gravidade da doença e resposta ao tratamento ${ }^{32}$.

O genótipo B é associado a altas taxas de soroconversão do $\mathrm{HB} e \mathrm{Ag}$ para anti-HBe quando comparadas com o genótipo $\mathrm{C}^{2127}$. A seleção da mutação pré-core (anti-HB $e$ reativo) é relatada entre portadores do genótipo $\mathrm{B}$, a variante pré-core é mais comum em pacientes com genótipo $\mathrm{D}$ e raramente entre os com genótipo $\mathrm{A}$. Portadores do VHB mutante pré-core ou promoter core basal (hepatite crônica B HBeAg negativo) com genótipo D apresentam resistência significativa à lamivudina $(\mathrm{rtM} 2041)^{27}$. Em Taiwan, 0 genótipo B do VHB predomina entre crianças portadoras crônicas do VHB e com quadro de câncer de fígado ${ }^{27}$. Por outro lado, crianças portadoras do genótipo C do VHB apresentam: maior frequiência de soroconversão para o $\mathrm{HB} e \mathrm{Ag}$, alta freqüência de mutação core promoter, alta atividade das aminotransferases e, finalmente, baixa resposta à terapia com Interferon alfa ${ }^{212732}$.

\section{HISTÓRIA NATURAL DA INFECÇÃO PELO VÍRUS DA HEPATITE B}

A história natural da infecção pelo VHB compreende três fases distintas. A primeira, definida com fase de imunotolerância. Esta fase comumente ocorre após o período de transmissão perinatal e é caracterizada pela presença sérica do $\mathrm{HBsAg}, \mathrm{HB} e \mathrm{Ag}$, altos títulos de HBV-DNA (10 ${ }^{5-10}$ cópias por m/L), ALT normal ou discretamente elevada, mínima lesão hepática histológica e curso assintomático 891214182324323340 . Estudos experimentais sugerem que a função primordial do $\mathrm{HB} e \mathrm{Ag}$ seria a de induzir ao portador do VHB $\left(\mathrm{HBsAg}^{+}\right)$o estado de imunotolerância ${ }^{32}$. Entre indivíduos expostos ao VHB na infância, a fase de imunotolerância pode permanecer por uma a quatro décadas ${ }^{32}$. Porém, quando as pessoas se infectam com o VHB durante a fase adulta de vida, não é observada a fase de imunotolerância. Pacientes que apresentam a referida fase são considerados de baixo risco de progressão para cirrose hepática e hepatocarcinoma 891214182324323340 .

A segunda fase é denominada de imunoativa ou de hepatite crônica $\mathrm{B}$, caracterizada pela presença no soro do $\mathrm{HB} e \mathrm{Ag}$ (VHB selvagem) ou do anti-HB $e^{+}$(VHB selvagem residual ou mutante pré-core) 891214152324323340 . A referida fase ocorre após a transmissão horizontal entre crianças ou na fase adulta. A fase imunoativa pode ocorrer também tardiamente entre pessoas que adquiriram a infecção pelo VHB durante a transmissão vertical (maternal), iniciando logo após a fase de imunotolerância. Elevados níveis da ALT, altos níveis de HBV-DNA e doença hepática ativa observada na biópsia caracterizam esta fase. Pacientes com hepatite crônica B HBeAg positivos podem apresentar soroconversão espontânea do HBeAg para o antiHBe, com elevação da ALT. Após soroconversão, observa-se níveis normais da ALT e títulos do HBV-DNA menor que 1000 $\mathrm{UI} / \mathrm{mL}\left(10^{3}\right.$ cópias $\left./ \mathrm{mL}\right)$. A soroconversão do HBeAg para antiHBe ocorre em 50\% das crianças e adultos após cinco anos e $70 \%$ após $10 \operatorname{anos}^{8912142324323340 .}$

A terceira fase é conhecida como não replicativa (portador inativo do $\mathrm{VHB}$ ), que se nota pela presença no soro do HBsAg, anti-HB $e$, títulos baixos ou indetectáveis do HBV-DNA, ALT normal, mínima lesão histológica hepática, curso assintomático e de bom prognóstico ${ }^{8912} 142324323340$. Muitos dos portadores inativos do VHB, 70\% a 90\%, permanecem inativos por toda a vida. Em área endêmica de infecção pelo VHB (Taiwan) observa-se 0 clareamento do HBsAg em cerca de $40 \%$ dos portadores inativos adultos, após seguimento de 29 anos $^{7}$. Um adicional de $10 \%$ a 20 \% dos portadores inativos apresentam fenômenos de reversão, caracterizado pelo reaparecimento do $\mathrm{HB} e \mathrm{Ag}$ (previamente $\mathrm{HB} e \mathrm{Ag}$ negativo e anti-HB $\boldsymbol{e}$ positivo $)^{7}$. 0 quadro de reversão é acompanhado usualmente de elevação da ALT em razão do processo de reativação inflamatória do fígado 7 . Um número bem 
menor de portadores inativos do VHB desenvolvem hepatite crônica $\mathrm{B}$ anti-HBe positivo (hepatite crônica residual pelo VHB selvagem) que se caracteriza por elevação dos níveis das aminotransferases, títulos de HBV-DNA maior que $20000 \mathrm{UI} / \mathrm{L}$ $\left(>10^{5}\right.$ cópias $\mathrm{m} / \mathrm{L}$ ) e doença hepática ativa (histológica) ${ }^{115}$. Invariavelmente, estes pacientes evoluem para cirrose hepática. Todavia, o curso clínico e as seqüelas de hepatite crônica pelo VHB selvagem ou mutante variam de indivíduo para indivíduo $0^{1891214152324323340}$.

A reativação do VHB é considerada por alguns autores com a quarta fase de infecção pelo VHB, ou seja, fase de reativaçã $0^{32} 40$. Todavia, nós consideramos a reativação do VHB como um fenômeno biológico característico dos hepadnavirus. A reativação do vírus B caracteriza-se pelo reaparecimento da atividade necroinflamatória do fígado em pessoas que sejam portadoras inativas do VHB ou que tenham recebido diagnóstico de hepatite B resolvida (infecção prévia pelo $\mathrm{VHB}$, sem sinais virológicos, bioquímicos ou evidência histológica de doença ativa viral) ${ }^{32}$.

Considerado um vírus hepatotrópico e não citopático, esse agente viral pode causar doença hepática aguda ou fulminante, hepatite crônica e cirrose hepática ${ }^{2324}{ }^{42}$. Estudos epidemiológicos revelam uma intrínseca relação entre a infecção pelo VHB e 0 câncer de fígado ${ }^{35}$. 0 tempo de infecção e os altos níveis do HBV-DNA observados durante a infecção crônica pelo VHB são fatores que poderiam influenciar a incidência cumulativa de carcinoma hepatocelular ${ }^{35}$. Pacientes chineses portadores do HBsAg que negativaram o referido antígeno durante determinado período de seguimento, observou-se que $37 \%$ tinham o HBVDNA intra-hepático e 5,4\% destes desenvolveram carcinoma hepatocelular (CHC) ao longo do tempo $0^{42}$. Segundo os autores, estes achados sugerem que o CHC pode se desenvolver mesmo após o clareamento (negativação) do $\mathrm{HBsAg}^{42}$. Em Taiwan, estudos realizados entre 3653 portadores do $\mathrm{VHB}$ concluíram que níveis séricos do HBV-DNA maior que $10^{4}$ cópias /mL (> $2000 \mathrm{UI} / \mathrm{L}$ ) seriam um grande risco e fator preditivo no desenvolvimento de $\mathrm{CHC}^{5}$. Durante o ciclo do VHB no humano, observa-se a integração do genoma do VHB nas células cromossômicas em $85 \%$ dos pacientes com carcinoma hepatocelular associado ao $\mathrm{VHB}^{3}$.

Elevações substanciais e espontâneas da ALT (flares) ocorrem freqüentemente na história natural da hepatite crônica $B^{20} 22353236$, em decorrência de diversos fatores etiológicos, como podemos observar na Tabela 1. A ocorrência de co-infecção ou superinfecção aguda por outros agentes virais (VHA,VHC, VHD, HIV, Parvovirus B19) entre portadores do HBsAg pode influir na história natural do VHB, ocasionando o que se segue: curso fulminante ou severo na hepatite aguda, forma crônica de hepatite cursando com maior gravidade ou de rápida progressão para cirrose hepática e carcinoma hepatocelular, quando comparados com aqueles infectados somente pelo $\mathrm{VHB}^{111326353639}$.

Portadores crônicos do VHB $\left(\mathrm{HBsAg}^{+}+\right.$anti-HBe $\left.e^{+}\right)$, originalmente infectados com o genótipo $B$, podem sofrer um processo de superinfecção aguda pelo VHB com genótipo C e desenvolver hepatite aguda, cursando com aumento da ALT e positividade para a fração anti-HBc $\operatorname{IgM}^{20}$. Estudos
Tabela 1 - Principais fatores responsáveis pelas elevações temporárias e espontâneas das aminotransferases entre portadores do vírus da bepatite $B$.

- Reativação espontânea da hepatite crônica B por uso de drogas imunossupressoras (quimioterápicos, corticosteróide, drogas anti-rejeição)

- Resultante de terapêutica antiviral (interferon, núcleos(t)ideos )

- Induzido por variação genotípica do VHB (pré-core, core promoter, HBV-DNA polimerase)

- Interação com HIV infecção

- Superinfecção por outros vírus hepatotrópicos e não hepatotrópicos.

recentes revelam que pacientes vietnamitas portadores do VHB apresentaram uma alta prevalência de infecção pelo parvovírus $B 19^{39}$. Segundo os autores, pacientes portadores do VHB quando infectados pelo B19 apresentam curso clínico e progressão da doença hepática crônica B mais grave, com evolução freqüente para cirrose hepática e carcinoma hepatocelular ${ }^{39}$. Porém, desconhece-se a verdadeira participação do B19 na patogênese a mudança do curso clínico entre pacientes infectados pelo VHB e 0 potencial viral latente da interação viral entre os dois agentes ${ }^{39}$.

\section{DIAGNÓSTICO DA INFECÇÃo PELO VÍRUS DA HEPATITE B}

Na infecção primária pelo VHB detecta-se 0 HBsAg (primeiro marcador sorológico) no sangue após um período de incubação de quatro a 12 semanas, seguido pelo anticorpos contra 0 antígeno central do VHB (anti-HBc IgG e IgM).0 antígeno $e$ do VHB (HBeAg) aparece concomitante com o HBsAg, desaparecendo precocemente em média de 15 dias $^{24}$. Durante 0 aparecimento do HBsAg observa-se ao mesmo tempo uma alta viremia do VHB (níveis séricos variando de $10^{9} \mathrm{a} 10^{10}$ virions por mililitro). No momento primário da infecção aguda pelo $\mathrm{VHB}, 75 \%$ a $100 \%$ dos hepatocitos estariam infectados. As aminotransferases só elevariam seus níveis séricos (fase aguda) após a infecção pelo VHB estiver devidamente estabelecida, refletindo assim no tempo para gerar uma resposta imuno-mediada pelas células $\mathrm{T}^{24}$.

Com a resolução da infecção pelo VHB, os antígenos virais HBsAg e HBeAg desaparecem da circulação e 0 anti-HBs começa a ser detectado no soro. Após a resolução da infecção, alguns pacientes, mesmo sendo anti-HBs positivo, podem cursar com títulos positivos para o HBV-DNA por um longo período de anos ou por toda a vida.

A persistência deste antígeno viral (HBsAg) no soro por mais de seis meses indicaria infecção crônica pelo $\mathrm{VHB}^{24}$. Entre os portadores crônicos do HBsAg a presença do HBeAg indicaria alta replicação viral, contudo sua ausência não pode ser caracterizada como tal, já que pacientes HBeAg negativo e anti$\mathrm{HB} e$ positivos (mutante pré-core) podem apresentar significativa replicação viral ${ }^{15} 16{ }^{19}$. Geralmente, a presença do anti-HBe indicaria soroconversão do $\mathrm{HB} e \mathrm{Ag}$, mas sabemos que o anti-HBe é também detectado entre portadores do mutante pré-core ${ }^{115}$.

Na Tabela 2 podemos observar os diversos padrões sorológicos da infecção crônica pelo VHB. Como podemos observar na referida tabela, o padrão sorológico da infecção pelo VHB mutante é idêntico ao do portador inativo do VHB, daí a necessidade de 
Tabela 2 - Padrões sorológicos da infecção crônica pelo VHB

\begin{tabular}{lcccccc} 
Marcadores & HBsAg & HBeAg & Anti-HBe & Anti-HBc* & Anti-HBs & HBV-DNA \\
\hline Infecção crônica VHB & + & + & - & + & - & + \\
Infecção oculta VHB & - & - & - & + & - & + \\
Portador inativo VHB & + & - & + & + & - & + \\
Pré-core mutante & + & - & + & + & - & + \\
Infecção passada & - & - & - & $+/-$ & + & - \\
\hline
\end{tabular}

*Anti-HBc total, + positivo, - negativo.

quantificarmos a carga viral do vírus B. Dependendo dos níveis séricos do HBV-DNA encontrados, de idade maior que 40 anos, podemos indicar a biópsia hepática ${ }^{6} 832$. Nos dois grupos de portadores crônicos do VHB a ALT pode permanecer normal ou apresentar aumentos intermitentes. Portanto, a ALT não serve como parâmetro no diagnóstico diferencial sorológico e de estádio de infecção.

Dizemos que a infecção crônica pelo VHB é resolvida quando o paciente apresenta: história prévia de hepatite crônica, positividade sorológica para o anti-HBc total \pm anti-HBs, HBsAg negativo, níveis normais de ALT e HBV-DNA sérico indetectável.

\section{INFECÇÃO OCULTA PELO VÍRUS DA HEPATITE B}

A detectação no soro do HBV-DNA sem o HBsAg sérico, com ou sem a presença dos anticorpos do VHB (anti-HBc total isolado ou associado ao anti-HBs), definiria o estado de infecção oculta pelo vírus $\mathrm{B}^{31}{ }^{37}$. Esta condição é constantemente observada entre os mais diversos estádios clínicos de infecção e doença ocasionada pelo vírus B, tais como: portadores inativos, hepatite crônica, cirrose hepática, carcinoma hepatocelular. Nas áreas endêmicas de infecção pelo VHB, como a região Amazônica brasileira, um número significativo de pacientes com cirrose hepática são negativos para o HBsAg (68,4\%) e apresentam-se sorologicamente positivo para o anti-HBc total isolado ou associado ao anti-HBs ${ }^{11}$. Indivíduos sem marcadores sorológicos do VHB e portadores de hepatite crônica C podem cursar com infecção oculta pelo vírus $\mathrm{B}^{3137}$.

A prevalência de soropositividade do HBV-DNA em indivíduos HBsAg negativos varia de $0-10 \%$ entre os sem doença hepática, $11-19 \%$ nos pacientes com hepatite crônica, 12-61\% entre portadores de carcinoma hepatocelular e $1-95 \%$ em pacientes com hepatite crônica $\mathrm{C}^{43138}$. A prevalência do HBV-DNA é sempre maior nos indivíduos sabidamente negativos para o HBsAg, mas soropositivos para o anti-HBc total e anti-HBs. Estudos recentes revelam que, entre pacientes com infecção oculta pelo vírus $B$, prevalece a cepa variante-S do VHB, 52 a $86 \%^{3137}$.

Até o presente momento não se sabe explicar qual ou quais os mecanismos moleculares ou imunológicos da infecção oculta pelo VHB. Porém, diversas hipóteses são propostas para explicar a ocorrência de tal infecção oculta e as mais aceitas seriam: mutação S, core e X dos genes do VHB; integração do HBVDNA no genoma do hospedeiro; formação de imunocomplexos circulantes contendo o VHB; alteração da resposta imune do hospedeiro ao VHB; superinfecção e interferência por outro vírus no vírus $B^{4}{ }^{31}{ }^{37}$. A infecção oculta pelo VHB pode ser transmitida através de transfusões de sangue e hemoderivados, hemodiálise e órgãos transplantados ${ }^{28}$.

O impacto clínico da infecção oculta pelo VHB pode ser observado nas seguintes circunstâncias: reativação do VHB entre pacientes usando drogas imunossupressoras, provocando inclusive hepatite fulminante; exacerbação aguda na hepatite crônica B; desenvolvimento de carcinoma hepatocelular; maior gravidade da doença hepática crônica ocasionada pelo VHC. A flutuação cumulativa e constante dos níveis do HBV-DNA entre portadores de hepatite crônica $C$ pode elevar os níveis da ALT e consequientemente alterar o curso clínico e histológico da doença ${ }^{3137}$.

A presença isolada do anti-HBc total entre pacientes infectados pelo HIV é bastante significativa e pode variar de $10 \%$ a $45 \%{ }^{22} 36$. A positividade para o HBV-DNA sérico entre esses é freqüente, caracterizando assim uma provável infecção oculta pelo VHB. Portanto, recomenda-se sempre que entre os pacientes infectados pelo HIV sejam realizados testes sorológicos dos marcadores de infecção pelo VHB, inclusive HBV-DNA ${ }^{22}$. A infecção oculta pelo VHB deve ser caracterizada pela ausência total de marcadores da infecção pelo VHB (antígenos e anticorpos) e positividade persistente do HBV-DNA no soro ou no fígado ${ }^{22} 36$. Contudo, para um diagnóstico preciso da infecção oculta pelo VHB, devemos utilizar técnicas de PCR ultra-sensível com detectação limite menor que 10 cópias do HBV-DNA.

\section{HISTÓRIA NATURAL DA HEPATITE CRÔNICA B}

0 risco de progressão para hepatite crônica na infecção pelo VHB ocorre em 5-10\% dos adultos e em $90 \%$ dos neonatos ${ }^{24}$. Nas formas ictéricas de hepatite aguda, observa-se em adultos um percentual de apenas $2 \%$ com progressão para hepatite crônica. $\mathrm{Na}$ história natural do VHB selvagem, a persistência do HBsAg, HBeAg e altos títulos do HBV-DNA por mais de seis meses, implica na progressão da infecção crônica pelo $\mathrm{VHB}^{32}$.

A hepatite crônica B pode ser separada em duas formas distintas. A primeira é baseada na presença do $\mathrm{HB} e \mathrm{Ag}$ no soro (vírus B selvagem), enquanto a segunda forma, na ausência do $\mathrm{HB} e \mathrm{Ag}$ e presença sérica do anti-HB $e$ (vírus B selvagem residual ou mutante core). A mutação pré-core 1896/1899 (hepatite crônica $\mathrm{B}$ anti-HB $e^{+}$) resulta da síntese defectiva do $\mathrm{HB} e$ Ag que originaria um códon de terminação, ocasionado assim a seleção de cepas variantes que não produzem o $\mathrm{HB} e \mathrm{Ag}^{15}{ }^{15}$. Por outro lado, a existência marcante do $\mathrm{HB} e \mathrm{Ag}$ nas células infectadas estimulariam os linfócitos T citotóxicos há uma resposta imunecelular, consequentemente, cepas emergentes e mutantes do VHB seriam selecionadas, tentando escapar da pressão dos linfócitos T e $\mathrm{B}^{115213038}$. Provavelmente, a origem do mutante pré-core 1896 estaria relacionada com a vantagem de sobrevida sobre as cepas do VHB produtoras do $\mathrm{HB} e \mathrm{Ag}$.

A incidência anual de cirrose hepática varia de $2 \%$ a $6 \%$ entre pacientes com hepatite crônica $\mathrm{HB} e \mathrm{Ag}$ positivos e de $8 \%$ a $10 \%$ nos pacientes com hepatite crônica $\mathrm{HB} e \mathrm{Ag}$ negativos ${ }^{24} 32$. Diversos fatores podem influenciar o prognóstico e a progressão da hepatite 
crônica B para cirrose hepática, como podemos verificar na Tabela 3. A alta incidência de cirrose hepática nos pacientes com hepatite crônica $\mathrm{HB} e \mathrm{Ag}$ negativos ou hepatite crônica anti-HBe positivo está relacionada com a idade mais avançada ( $>35$ anos de idade) e doença mais avançada na sua apresentaçãa ${ }^{15}$. Entre pacientes infectados pelo HIV, a infecção pelo VHB aumenta o risco de cirrose hepática, morte por insuficiência hepática, especialmente quando os níveis séricos de $\mathrm{CD}_{4}$ encontram-se baixos ou pelo uso concomitante de álcool ${ }^{22}{ }^{36}$. Com relação aos fatores de risco para carcinoma hepatocelular, os mais importantes podem ser observados na Tabela 4.

Tabela 3 - Principais fatores que podem influenciar o prognóstico e a progressão da bepatite crônica B para cirrose hepática.

- Pertencer ao sexo masculino

- Idade maior que 35 anos ao tempo do diagnóstico

- Gravidade da atividade necroinflamatória hepática (histológica)

- Positividade para o $\mathrm{HB} e \mathrm{Ag}$

- Mutação pré-core 1896 (hepatite crônica anti-HBe ${ }^{+}$)

- Elevados níveis séricos da alaninaaminotransferase (ALT)

- Episódios recorrentes de grave exacerbação aguda com formação de necrose hepática em ponte

- Flutuação dos níveis de replicação do VHB em pacientes HBeAg negativos

- Genótipo C associado a alto risco de cirrose (pacientes asiáticos)

- Alta carga viral

- Coinfecção ou superinfecção aguda viral (VHC,VHD, HIV, parvovírus B19)

- Uso crônico de bebidas alcoólicas

- $\quad$ Etnia (Asiática)

- Tabagismo crônico

- Homem que faz sexo com homem portador de hepatite crônica B e HIV reativo (altos níveis de replicação do VHB)

Tabela 4 - Principais fatores de risco para o desenvolvimento de carcinoma bepatocelular em portadores do vírus da bepatite $B$.

- Sexo masculino

- História familiar de carcinoma hepatocelular

- Idade maior que 45 anos de idade

- Presença do HBeAg em adultos (> 40 anos)

- História de reversão sorológica do anti-HBe para HBeAg

- Níveis elevados e persistentes do HBV-DNA sérico*

- Integração do genoma do VHB (HBV-DNA) no genoma do fígado do hospedeiro

- Influência dos genótipos do VHB?

- Mutações no genoma viral (pré-core, , core promoter, região X)

- Presença de aflatoxinas nos alimentos

- Presença de cirrose hepática

- Coinfecção com o VHC ou VHD

- Uso de álcool

*Fator independente do status do HBeAg, dos níveis de ALT e do tipo de genótipo do VHB.

\section{HEPATITE CRÔNICA B}

Hepatite crônica $\mathrm{HBeAg}$ positivo. A hepatite crônica B-HBeAg ${ }^{+}$ caracteriza-se por: maior ocorrência na fase precoce da infecção crônica pelo VHB; predomínio no sexo masculino; média de idade de 31 anos; estar associada à alta infectividade; altos títulos do
HBV-DNA; atividade necroinflamatória hepática menos agressiva que na hepatite crônica (anti-HB $e^{+}$). A doença provocada pelo vírus B selvagem $\left(\mathrm{HB} e \mathrm{Ag}^{+}\right)$cursa assintomaticamente por três a quatro décadas e observa-se processo de cirrotização hepática entre os 40 e 45 anos de idade 891214233233 .

Nos pacientes com hepatite crônica B HBe $\mathrm{Ag}^{+}$, a soroconversão espontânea do $\mathrm{HB} e \mathrm{Ag}$ para anti-HBe ocorre comumente, precedida pela queda dos níveis de HBV-DNA, de $10^{7}-10^{10}$ cópias por $\mathrm{m} / \mathrm{L}$ para menos que $10^{5}$ cópias por $\mathrm{m} / \mathrm{L}$ e elevação da ALT (flare). Após soroconversão do $\mathrm{HB} e \mathrm{Ag}$ para anti-HBe, muitos pacientes apresentam ALT normal e queda dos níveis de HBVDNA, usualmente $<10^{3}$ cópias $/ \mathrm{mL}$. A redução da replicação viral durante a soroconversão do HBeAg para anti-HBe estaria também associada também a regressão da atividade histológica inflamatória hepática e bioquímica ${ }^{891214233233}$. Estudos longitudinais revelam a probabilidade de clareamento do HBeAg após 5 (50\%) e 10 (70\%) anos do diagnóstico sorológico ${ }^{32}$.

Recentemente, estudo de caráter coortico entre 70 pacientes caucasianos com hepatite crônica $\mathrm{B} \mathrm{HBe} \mathrm{Ag}^{+}$revelou que após seguimento médio de 25 anos, 61 (87\%) tinham soroconvertido o HBeAg espontaneamente'. Nesse mesmo estudo, durante um período médio de 22,8 anos após soroclareamento do $\mathrm{HB} e \mathrm{Ag}, 40$ (66\%) dos pacientes tornaram-se portadores inativos do VHB. A soroconversão do HBeAg usualmente representa a transição da hepatite crônica B para o estado de portador inativo do VHB. De acordo com os autores, no período de 25 anos $11(15,75)$ casos de óbitos foram relacionados com doença hepática, sendo cinco causados por carcinoma hepatocelular e seis por insuficiência hepática9.

0 diagnóstico da hepatite crônica B-HBeAg ${ }^{+}$é baseado no estado de portador do HBsAg por mais de seis meses, anti-HBe negativo, aumento da ALT (persistente ou intermitente), níveis séricos de HBV-DNA excedendo $10^{5}$ a $10^{6}$ cópias por $\mathrm{m} / \mathrm{L}$ e atividade histológica necroinflamatória hepática ${ }^{32}$.

Hepatite crônica B anti-HBe positivo. A hepatite crônica $\mathrm{B}-$ anti-HB $e^{+}$apresenta as seguintes características: pode ser ocasionada pelo VHB selvagem (wild type) residual ou pelo vírus mutante B pré-core (G1896 $\rightarrow$ A, Códon 28), este último considerado a maior causa dessa forma de hepatite crônica $B^{1,15,32}$ ocorre durante a fase tardia da infecção crônica B; prevalece no sexo masculino; a média de idade é de 40 anos. Quando

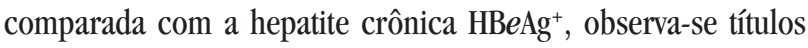
mais baixos de HBV-DNA $\left(<10^{5}\right.$ cópias por $\mathrm{m} / \mathrm{L}$ ) e a atividade necroinflamatória hepática é mais grave, com evolução inexorável para cirrose hepática ${ }^{15}{ }^{32}$. Estudos realizados entre pacientes chineses portadores do HBsAg com quadro de cirrose hepática descompensada, 67,\% eram anti-HBe $e^{+}, 37,7 \%$ tinham títulos de HBV-DNA menor que $10^{5}$ cópias/mL $(<20000 \mathrm{UI} / \mathrm{L})$ e $24,5 \%$ apresentavam títulos de HBV-DNA menores que $10^{4}$ cópias $/ \mathrm{mL}$ $(<2000 \mathrm{UI} / \mathrm{L})^{32}$.

0 diagnóstico da hepatite crônica $\mathrm{B}$ anti-HBe $e^{+}$baseia-se nos seguintes parâmetros: $\mathrm{HBsAg}^{+}$sérico por mais de seis meses, HBV-DNA no soro $<10^{5}$ cópias por $\mathrm{m} / \mathrm{L}$, aumento e flutuação da ALT no curso da infecção, positividade para a fração anti-HBc IgM durante elevação da ALT ( $80 \%$ dos pacientes), altos títulos de 
HBV-DNA precedem elevação da ALT, presença documentada do antígeno central do VHB (HBcAg) nos hepatócitos, ausência de marcadores sorológicos do VHD e VHC ${ }^{1532}$. Resumindo, podemos concluir que na clínica diária, pacientes com ALT elevada, HBsAg, anti-HBe e HBV-DNA positivos devam ser considerados suspeitos de infecção pelo vírus da hepatite B mutante pré-core.

\section{REFERÊNCIAS}

1. Bonino F, Brunetto MR. Chronic hepatitis B e antigen (HBeAg) negative, anti-HBe positive hepatitis B: an overview. Journal of Hepatology 39: S160-S163, 2003.

2. Bouchard MJ, Schneider RJ. The enigmatic $X$ gene of hepatitis B virus. Journal of Virology 78: 12725-12734, 2004.

3. Bréchot C. Pathogenesis of hepatitis B virus-related hepatocellular carcinoma: old and new paradigms. Gastroenterology 127: S56-S61, 2004.

4. Chen A-J. Time dependents events in natural history of occult hepatitis B virus infection: the importance of population-based long-term follow-up study with repeated measurements. Journal of Hepatology 42: 438-440, 2005

5. Chen CJ, Yang HI, Su J, Jen CL, You SL, Lu SN, Huang GT, Iloeje UH, Reveal-HBV Study Group. Risk of hepatocellular carcinoma across a biological gradient of serum hepatitis B virus DNA level. Journal of American Medical Association 295: 65-73, 2006

6. Chu C-J, Lok AS. Clinical utility in quantifying serum HBV-DNA levels using PCR assays. Journal of Hepatology 36: 549-551, 2002.

7. Chu CM, Liaw YF. HBsAg seroclearance in asymptomatic carriers of high endemic areas: appreciably high rates during a long-term follow-up. Hepatology 45: 1187$1192,2007$.

8. Conjeevaram HS, Lok AS. Management of chronic hepatitis B. Journal of Hepatology 38: S90-S103, 2003.

9. Fattovich G. Natural history of hepatitis B. Journal of Hepatology 39: S50-S58, 2003.

10. Fattovich G, Olivari, Pasino M, D' Onofrio M, Martone E, Donato F. Long-term outcome of chronic hepatitis B in Caucasian patients: mortality after 25 years. GUT. Published Online First: 22 August 2007. doi:10.1136/gut.2007.128496, 2007.

11. Fonseca JCF. Hepatite Delta. Revista da Sociedade Brasileira de Medicina Tropical 35: 181-190, 2002.

12. Fung SK, Lok ASF. Management of patients with hepatitis B virus-induced cirrhosis. Journal of Hepatology 42: S54-S64, 2005.

13. Gaeta GB, Precone DF, Cozzi-Lepri A, Cicconi P, D'Arminio Monforte A. Multiple viral infections. Journal of Hepatology 44: 108-113, 2006.

14. Ganem D, Prince AM. Hepatitis B virus infection - Natural history and clinical consequences. The New England Journal of Medicine 350: 1118-1129, 2004.

15. Hadziyannis SJ, Vassilopoulos D. Hepatitis B e antigen-negative chronic hepatitis B. Hepatology 34: 617-624, 2001.

16. Hatzakis A, Magiorkinis, E Haida C. HBV virological assessment. Journal of Hepatology 44: 71-76, 2006.

17. Hui CK, Leung N, Shek TW, Yao H, Lee WK, Lai JY, Lai ST, Wong WM, Lai LS, Poon RT, Lo CM, Fan ST, Lau GK, Hong Kong Liver Fibrosis Study Group. Sustained disease remission after spontaneous $\mathrm{HBeAg}$ seroconversion is associated with reduction in fibrosis progression in chronic hepatitis B Chinese patients. Hepatology 43: 690-698, 2007

18. Hui CK, Leung N, Yuen ST, Zhang HY, Leung KW, Lu L, Cheung SK, Wong WM, Lau GK, Hong Kong Liver Fibrosis Study Group. Natural history and disease progression in Chinese chronic hepatitis B patients in immune-tolerant phase. Hepatology 46: 395-401, 2007.
19. Hunt CM, McGill JM, Allen ML, Condreay LD. Clinical relevance of hepatitis B viral mutations. Hepatology 31: 1037-1044, 2000.

20. Kao J-H, Chen P-J, Lai M-Y, Chen DS. Acute exacerbations of chronic hepatitis B are rarely associated with superinfection of hepatitis B virus. Hepatology 34: 817-823, 2001.

21. Kidd-Ljunggren, Miyakawa Y, Kidd AH. Genetic variability in hepatitis B viruses. Journal of General Virology 83: 1267-1280, 2002.

22. Koziel MJ, Peters MG. Viral hepatitis in HIV infection. The New England Journal of Medicine 356: 1445-1454, 2007.

23. Lavanchy D. Hepatitis B virus epidemiology, disease burden, treat, and current and emerging and control measures. Journal of Viral hepatitis 11: 97-107, 2004.

24. Lee WM. Hepatitis B virus infection. The New England Journal of Medicine 337: 1773-1745, 1997.

25. Liang TJ, Ghany M. Hepatitis B e antigen - The dangerous endgame of hepatitis B. The New England Journal of Medicine 347: 208-210, 2002.

26. Liaw YF, Chen YC, Sheen IS, Chien RN, Yeh CT, Chu CM. Impact of acute hepatitis $\mathrm{C}$ virus superinfection in patients with chronic hepatitis B virus infection. Gastroenterolgy 126: 1024-1029, 2004.

27. Liu CJ, Kao JH. Hepatitis B virus genotype: what the should clinician know? Current Hepatitis Reports 6: 17-23, 2007.

28. Liu CJ, Lo SC, Kao JH, Tseng PT, Lai MY, Ni YH, Yeh SH, Chen PJ, Chen DS Transmission of occult hepatitis B virus by transfusion to adult and pediatric recipients in Taiwan. Journal of Hepatology 44: 39-46, 2006.

29. Locarnini S. Hepatitis B viral resistance: mechanisms and diagnosis. Journal of Hepatology 39: S124-S132, 2003.

30. Locarnini S. Molecular virology of hepatitis B virus. Seminars in Liver Disease 24 (supplement 1): 3-10, 2004.

31. Lok ASF. Occult hepatitis B virus infection: diagnosis, implication and management. Journal Gastrenterology Hepatology 19: S114-S117, 2004.

32. Lok ASF, McMahon BJ. Chronic hepatitis B. Hepatology 45: 507-539, 2007.

33. McMahon BJ. The natural history of chronic hepatitis B virus infection. The New England Journal of Medicine 337: 1773-1745, 1997.

34. Neumann AU. Hepatitis B viral kinects: A dynamic puzzle still to be resolved. Hepatology 42: 249-254, 2005.

35. Perrilo RP. Acute flares in chronic hepatitis B: The natural an unnatural history of an immunologically mediated liver disease. Gastroenterolgy 120: 1009-1022, 2001.

36. Puoti M, Torti C, Bruno R, Felice G, Carosi G. Natural history of chronic hepatitis B in co-infected patients. Journal of Hepatology 44: S65-S70, 2006.

37. Raimondo G, Pollicino T, Cacciola I, Squadrito G. Occult hepatitis B virus infection. Journal of Hepatology 46: 160-170, 2007.

38. Raimondo G, Pollicino T, Squadrito G. Clinical virology of hepatitis B virus infection. Journal of Hepatology 39: S26-S30, 2003.

39. Toan, NL, Song LH, Kremsner PG, Duy DN, Binh VQ, Duechting A, Kaiser H, Torresi J, Kandolf R, Bock CT. Co-infection of human parvovirus B19 in Vietnamese patients with hepatitis B virus infection. Journal of Hepatology 45: 361-369, 2006.

40. Wright TL. Introduction to chronic hepatitis B infection. The American Journal of Gastroenterolgy 101: S1-S6, 2006.

41. Yang HI, Lu SN, Liaw YF, You SL, Sun CA, Wang LY, Hsiao CK, Chen PJ, Chen DS. Hepatitis B e antigen and the risk of hepatocellular carcionoma. The New England Journal of Medicine 347: 168-174, 2002

42. Yuan HJ, Yuen MF, Ka-Ho Wong D, Sablon E, Lai CL.The relationship between HBV-DNA levels and cirrhosis-related complications in Chinese with chronic hepatitis B. Journal of Viral Hepatitis 12: 373-379, 2005. 